of delayed coincidences with variable delay-time, receive no mention, and the reviewer has detected a few definite mistakes in the circuit diagrams. In a few places throughout the book, too, the derivation of the formulæ used is not completely clear, and another minor criticism is the use, without definition, of the term 'pre-dissociation'; in view of the importance attached to this process in self-quenching Geiger counters, we feel the term should have been explained.

It is recognized that it is difficult to produce a satisfactory book in a field in which research is still active, and in particular in a field where, as in Geiger counters, much past work has been of the empirical 'cook-book' variety. Within the compass of the present volume, and granted its emphasis on the internal mechanism, it would be difficult to suggest any important improvements. The need for such a book is undoubted, and this one will be of use to the specialist and the general user of counters alike.

C. H. WestcotT

\section{ON UNDERSTANDING SCIENCE}

\section{On Understanding Science}

An Historical Approach. By James B. Conant. (The Terry Lectures.) Pp. Xv + 146. (London: Oxford University Press, 1947.) 10s. 6d. net.

$I^{\mathrm{N}}$ $\mathrm{N}$ this book the President of Harvard University addresses himself to the problem of preparing suitable university courses (whether for graduates or undergraduates is not clear) for the purpose of producing an understanding of science in those whose future work is not to be scientific. He gives reasons why he thinks this important. By "understanding science" Dr. Conant means the acquiring of the special point of view which the successful investigator in a field of experimental science naturally attains, and he considers that this end can be achieved better by the presentation of selected 'case-histories' of particular advances in science than by a philosophical analysis of science as a whole. As illustrations of such case-histories he chooses the investigations of the pressure and elasticity of air in the seventeenth century, the discovery of the galvanic battery, and the development and overthrow of the phlogiston theory. These are outlined, with frequent comments on appropriate digressions which the teacher might make to emphasize salient points.

The definition of science which is implied in these considerations is that "as a first approximation, we may say that science emerges from the other progressive activities of man to the extent that new concepts arise from experiments and observations, and the new concepts in turn lead to further experiments and observations"; and among the most important of the characteristics of scientific inves. tigation that are to be brought out are the influence of new techniques of experimentation and their connexion with the practical arts, the evolution of new concepts from experiment, the difficulties of experimentation and the significance of the controlled experiment, and the development of science as an organised social activity. Dr. Conant does not make the common modern error of transforming the fact that science has a social function into the illusion that science is a social function, and he is careful to distinguish the history of science from the history of technology; it is the former alone with which he is concerned. The book includes very useful bibliographies relating to the chosen case histories.

Taken as a whole, the book is both important and timely. The examples are admirably chosen and presented. It is claimed that the effort proposed would be a pioneer one, and so far as the United States is concerned (it is evident from various passages that this limitation is in Dr. Conant's mind) this may very well be so, although in Britain something similar has been in operation for some time. Perhaps experience of the working of the scheme might have led Dr. Conant to reconsider his contrast between the historical and philosophical approaches to the understanding of science. These can be made to supplement one another, and there is reason to hold that a course in the philosophy of science based on its whole history will lead to a better understanding of science than the mere recapitulation of selected past events alone, and will correct the error, almost inevitable when science is presented by means of special cases, of confusing casual with intrinsic characteristics. For example, such a course would suggest that the continuously progressive element in science is the growth of the field of correlated observations, and not, as Dr. Conant suggests, "changing concepts and evolving conceptual schemes". Newtonian mechanical science pro. gressed enormously for more than two hundred years with scarcely any changing concepts and evolving conceptual schemes. Again it might help to elucidate the difficulty which arises when Dr. Conant emphasizes the (questionable) "differences in method between the observational sciences... on the one hand, and the experimental sciences... on the other", but draws all his case histories from the latter.

Such points, however, though important, are of secondary importance. It is much to be hoped that Dr. Conant's book will be widely read and will bear fruit.

Herbert Dingle

\section{DESTRUCTION AND REHABILITA. TION OF AN ISLAND FAUNA}

The Fauna of Krakatau, 1883-1933

By K. W. Dammerman. (Verhandelingen der Koninklijke Nederlandsche Akademie van Weten. schappen, Afd. Natuurkunde, Sectie 2, Deel 14.) Pp. xii $+594+11$ plates. (Amsterdam: N. V. Noord-Hollandsche Uitgevers Mij., 1948.) n.p.

$\mathrm{P}$

RIOR to 1883 there existed in the Sunda Straits between Sumatra and Java three small islands, the largest of which, Krakatau, was composed of three active volcanoes, Perboewatan, Danan and Rakata. From May 20 until August 28, 1883, \& series of volcanic eruptions succeeded one another until with a final and stupendous explosion the two volcanoes, Danan (400 m.) and Perboewatan, disappeared entirely, and Rakata $(800 \mathrm{~m}$.) was split right through the middle, one half of it together with the other two volcanoes sinking into the depths of the ocean, while a cavity $270 \mathrm{~m}$. deep was made in the sea-bed. The main island was originally $9 \mathrm{~km}$. long by $5 \mathrm{~km}$. in breadth with a surface area of 33 sq. $\mathrm{km}$., of which $22 \mathrm{sq}$. $\mathrm{km}$. sank beneath the sea. Thirty-six thousand people in Java and Sumatro were killed by the resulting sea wave. 